\title{
Swimming-induced pulmonary edema: current perspectives
}

This article was published in the following Dove Press journal: Open Access Journal of Sports Medicine

\author{
Ralph Smith' \\ Julian O M Ormerod ${ }^{2}$ \\ Nikant Sabharwal ${ }^{2}$ \\ Courtney Kipps ${ }^{3}$ \\ 'Department of Sport and Exercise \\ Medicine, Nuffield Orthopaedic \\ Centre, Oxford University Hospitals \\ NHS Trust, Oxford, UK; ' 2 Department \\ of Cardiology, John Radcliffe Hospital, \\ Oxford University Hospitals NHS \\ Trust, Oxford, UK; Institute of Sport, \\ Exercise and Health, Division of \\ Surgery and Interventional Sciences, \\ UCL, London, UK
}

Correspondence: Ralph Smith Department of Sport and Exercise Medicine, Nuffield Orthopaedic Centre, Oxford University Hospitals NHS Trust, Windmill Road, Oxford OX3 7LD, UK $\mathrm{Tel}+44(0) 1865738109$ Fax $+44(0) 1865738058$

Email ralph.Smith@doctors.org.uk

\begin{abstract}
With the growing popularity of water-based sports, cases of swimming-induced pulmonary edema (SIPE) are becoming increasingly recognized. SIPE, a potentially life-threatening condition, is an acute cause of breathlessness in athletes. It has been described frequently in scuba divers, swimmers, and triathletes and is characterized by symptoms and signs of pulmonary edema following water immersion. It is important to recognize that athletes' symptoms can present with a spectrum of severity from mild breathlessness to severe dyspnea, hemoptysis, and hypoxia. In most cases, there is rapid resolution of symptoms within 48 hours of exiting the water. Recent advances in the understanding of the pathophysiology of SIPE, particularly regarding exaggerated pulmonary vascular pressures, have begun to explain this elusive condition more clearly and to distinguish its predisposing factors. It is essential that event organizers and athletes are aware of SIPE. Prompt recognition is required not only to prevent drowning, but also to implement appropriate medical management and subsequent advice regarding return to swimming and the risk of recurrence. This manuscript provides a current perspective on SIPE regarding the incidence rate, the current understanding of the pathophysiology, clinical presentation, medical management, recurrence rates, and advice on return to sport.
\end{abstract}

Keywords: triathletes, open water swimming, diving, immersion, breathing difficulties

\section{Introduction}

With the increasing popularity of water-based events, such as triathlon and open water swimming, cases of swimming-induced pulmonary edema (SIPE) have become more frequently recognized. This rare cause of acute and occasionally fatal breathlessness was first described in the 1980s in apparently healthy scuba divers. ${ }^{1}$ Since then, over 300 cases have been described in scuba divers, military and recreational swimmers, and triathletes. ${ }^{2}$ Cases range from young, fit, military swimmers, ${ }^{3,4}$ who have undergone careful medical screening, to older recreational athletes and divers with preexisting cardiopulmonary disease. ${ }^{5} \mathrm{SIPE}$ is characterized by acute onset of dyspnea, cough, and occasionally hemoptysis, and is associated with water immersion. ${ }^{2}$ A key feature in the majority of cases is a rapid resolution of symptoms within 48 hours. Initial management requires safe water evacuation to prevent drowning and to perform a preliminary assessment. Symptoms usually begin to resolve after exiting the water and management may be supportive. Supplementary oxygen is important. Oxygen saturations are often low $(<92 \%)$, and there are often audible crepitations on auscultation of the chest. The affected individual is often transferred to hospital for further investigations and management. The prognosis is generally excellent when 
treated, though fatal cases have been reported. ${ }^{6}$ Recurrent episodes are unpredictable and are not uncommon. ${ }^{2}$ It has been proposed as a probable cause of unexplained death during swimming training in triathletes. ${ }^{7}$ While the exact pathophysiology remains elusive, a recent study suggests that there is an exaggerated rise in pulmonary artery and pulmonary artery wedge pressures (PAWPs) during exercise in SIPE susceptible individuals. ${ }^{8}$ It has been suggested that Sildenafil may play a role as an effective prophylactic agent against SIPE. ${ }^{8,9}$ Medical professionals and event organizers should be aware of SIPE in order to manage cases safely and avoid a delay in diagnosis. Furthermore, advice should be given on returning to activity and the risk of recurrence.

This manuscript provides a current perspective on SIPE regarding the incidence rate, the latest understanding of the pathophysiology, clinical presentation and management, recurrence rates, and advice on return to sport.

\section{Incidence and prevalence}

SIPE, also known as immersion pulmonary edema, has been described in a variety of water-based sporting activities predominantly in scuba divers, military and recreational swimmers, and triathletes. However, there are also cases described during snorkeling ${ }^{10}$ and aqua jogging. ${ }^{11}$

While there is now a considerable body of reported cases, relatively few studies have examined the incidence and prevalence. Estimates vary considerably; this is partly explained by the varying study methods and populations studied, which can make direct comparison challenging (Table 1).

Pons et al estimated the incidence of SIPE among scuba divers to be $1.1 \%$. Eighteen of the 460 scuba divers who responded to a questionnaire-based survey reported symptoms which were consistent with an episode of pulmonary edema. ${ }^{12}$ These suspected cases were then interviewed and five cases were confirmed. ${ }^{12}$ In a similar population, in an unpublished study, Keuski attempted to quantify the cumula-

Table I Shows the incidence and details of SIPE in reported cases

\begin{tabular}{|c|c|c|c|c|c|c|c|}
\hline Study & Context & Method and duration & $\begin{array}{l}\text { No of } \\
\text { cases }\end{array}$ & $\begin{array}{l}\text { Incidence } \\
\text { (\%) }\end{array}$ & $\begin{array}{l}\text { Age (years), } \\
\text { mean (range) }\end{array}$ & Comorbidities & $\begin{array}{l}\mathrm{N}=\text { Subjects with } \\
\text { recurrent episodes }\end{array}$ \\
\hline Smith et al ${ }^{16}$ & Triathletes & $\begin{array}{l}\text { Retrospective study of } \\
\text { medical records over a } \\
5 \text { year period }\end{array}$ & $5(2 M, 3 F)$ & $\begin{array}{l}5 / 68,557 \\
(0.007 \%)\end{array}$ & $42(2 I-58)$ & $\begin{array}{l}\text { I subject = Ischemic } \\
\text { heart disease, } \\
\text { hypercholesterolemia, } \\
\text { and hypertension } \\
\text { (details in Table 2) }\end{array}$ & $\begin{array}{l}2 \\
(40 \%)\end{array}$ \\
\hline $\begin{array}{l}\text { Ma and } \\
\text { Dutch }\end{array}$ & Triathletes & $\begin{array}{l}\text { Retrospective study of } \\
\text { medical records from } \\
\text { one Ironman triathlon } \\
\text { ( } 3.8 \mathrm{~km} \mathrm{swim,} 180 \mathrm{~km} \\
\text { bike and } 42.2 \mathrm{~km} \text { run) }\end{array}$ & I (M) & $\begin{array}{l}1 / 1594 \\
(0.06 \%)\end{array}$ & $57^{a}$ & $\begin{array}{l}\text { Hypertension, } \\
\text { hypercholesterolemia }\end{array}$ & Data not available \\
\hline$\overline{\text { Miller et al }{ }^{14}}$ & Triathletes & $\begin{array}{l}\text { Online self-reported } \\
\text { questionnaire }\end{array}$ & 20 & $\begin{array}{l}20 / 1400 \\
(1.4 \%)\end{array}$ & $(20-59)^{b}$ & Data not available & Data not available \\
\hline$\overline{\text { Keuski et al }{ }^{13}}$ & $\begin{array}{l}\text { Divers } \\
\text { (military) }\end{array}$ & $\begin{array}{l}\text { Survey medical } \\
\text { completed by medical } \\
\text { professional } \\
\text { (I-year period) }\end{array}$ & $\begin{array}{l}2 \\
\text { (confirmed } \\
\text { case) }\end{array}$ & $\begin{array}{l}2 / 2354 \\
(0.08 \%)\end{array}$ & $\begin{array}{l}\text { Data not } \\
\text { available }\end{array}$ & Data not available & Data not available \\
\hline $\begin{array}{l}\text { Adir } \\
\text { et } \mathrm{al}^{4}\end{array}$ & $\begin{array}{l}\text { Surface } \\
\text { swimming } \\
\text { (military) }\end{array}$ & $\begin{array}{l}\text { Field study over a } \\
\text { 3-year period }\end{array}$ & $70(\mathrm{M})$ & $\begin{array}{l}70 \text { cases } \\
(1.8 \%)\end{array}$ & $\begin{array}{l}18.5 \\
(18-19)\end{array}$ & $\mathrm{Nil}$ & $\begin{array}{l}\text { I6 }(22 \%) \\
\text { All recurrent episodes } \\
\text { occurred at least } 3 \\
\text { months following first } \\
\text { episode }\end{array}$ \\
\hline Shupak et al $\left.\right|^{3}$ & $\begin{array}{l}\text { Surface } \\
\text { swimming } \\
\text { (military) }\end{array}$ & $\begin{array}{l}\text { Field study } \\
\text { (2-month period) }\end{array}$ & $21(M)$ & $\begin{array}{l}21 / 35 \\
(60 \%)\end{array}$ & $\begin{array}{l}18.5 \\
(18-19)\end{array}$ & $\mathrm{Nil}$ & $6(28 \%)$ \\
\hline Pons et $\mathrm{a}^{12}$ & $\begin{array}{l}\text { Divers/ surface } \\
\text { swimming } \\
\text { (recreational) }\end{array}$ & $\begin{array}{l}\text { Survey with follow-up } \\
\text { medical review }\end{array}$ & $5(4 M, I F)$ & $\begin{array}{l}5 / 460 \\
(1.1 \%)\end{array}$ & $\begin{array}{l}27.8 \\
(23-39)\end{array}$ & $\mathrm{Nil}$ & $\begin{array}{l}\text { I female }(20 \%) \text { had } \\
4 \text { recurrent episodes: } \\
\text { I episode while scuba } \\
\text { diving and } 3 \text { while } \\
\text { surface swimming }\end{array}$ \\
\hline
\end{tabular}

Notes: aOnly one athlete with confirmed SIPE. bMean value was not given in this study.

Abbreviations: SIPE, swimming-induced pulmonary edema; $M$, male; F, female. 
tive incidence of SIPE at two US Navy diving training facilities. Surveys were completed by diving medical officers as cases presented over the course of year. Unfortunately, key information was missing in many data sheets. Thirty-one lacked complete chest radiograph data. Only two collected sheets were marked as positive for all five predetermined case criteria used yielding a $0.085 \%$ incidence of SIPE. ${ }^{13}$

During a 2-month field study of 35 male military swimmers who were participating in an open water (sea) training program $(2.4 \mathrm{~km}-3.6 \mathrm{~km})$, Shupak et al reported a considerably higher incidence rate. ${ }^{3}$ In this study, a clinical diagnosis of SIPE was made in swimmers who reported shortness of breath accompanied by cough. They encountered 29 events of SIPE in 21 individuals, and reported an incidence rate of $60 \%$. Twenty-one episodes were categorized as "mild" and eight as "severe". Episodes were categorized as mild when the swim trial was completed despite the appearance of symptoms, and severe when the participant had to stop swimming due to symptoms. There was a significant difference in oxygen saturations between symptomatic and asymptomatic individuals (91-96\% in symptomatic group vs $98 \%$ in asymptomatic group $P<0.001)$. However, in a similar population, Adir et al reported an incidence of $1.8 \%$ in a series of 70 cases of SIPE in military swimmers participating in sea-based time trials between 2.4 and $3.6 \mathrm{~km}$ (30-45 minutes in duration). ${ }^{4}$ The diagnostic criteria included acute onset of dyspnea, cough, and/or expectoration of frothy sputum, with evidence of pulmonary edema on physical examination and with no history of water aspiration. Miller et al, in 2010, found a similar rate of $1.4 \%$ in a survey of 1400 triathletes who had self-reported symptoms suggestive of SIPE. ${ }^{14} \mathrm{Ma}$ and Dutch published a case series of five triathletes, who presented with dyspnea and hemotypsis during or following a long-distance race. The race included 1594 competitors with a total of 147 encounters to the onsite medical team. Follow- ing clinical assessment, one case of SIPE was suspected. The patient was transported to the hospital for further care. Follow-up information was not available. ${ }^{15}$

More recently, authors from this paper conducted a retrospective analysis of 68,557 competitors' medical records from two large UK-based triathlon competitions over 5 consecutive years. ${ }^{16}$ Competitors were a mix of elite and non-elite triathletes who raced in a variety of triathlon distances from Super Sprint to Olympic Plus. We found an incidence of SIPE of $0.73 / 10,000$ triathletes, using the diagnostic criteria of Adir et al. ${ }^{4}$ These cases of SIPE accounted for $1.2 \%(5 / 429)$ of the presentations to the triathlon medical team. ${ }^{16}$ All were non-elite athletes competing in a variety of race distances; one patient had preexisting cardiac comorbidities, and three were competing in their first triathlon (Table 2). Each case failed to complete their race, and the majority (4/5) withdrew during/after the swim phase with one retiring during the bike phase. Supplementary oxygen and transfer to hospital for definitive management were required in all cases.

Possible explanations for these discrepancies in incident rate include:

1. Athletes may suffer a minor episode of SIPE which resolves quickly after exiting the water, and which they do not report to the medical teams. Hence, only the more severe episodes are documented. However, prospective studies actively seeking SIPE will detect these mild episodes.

2. Variations in diagnostic criteria used and populations studied.

\section{Predisposing factors}

Typical cases of SIPE demonstrate normal underlying cardiac and pulmonary function on further investigation. ${ }^{17}$ However, this may be less likely in older swimmer/divers, as an episode of SIPE may unmask other subclinical diseases. In a group

Table 2 Details of competitors presenting with SIPE during mass-participation triathlon races

\begin{tabular}{|c|c|c|c|c|c|}
\hline $\begin{array}{l}\text { Age, } \\
\text { years }\end{array}$ & Gender & $\begin{array}{l}\text { Race } \\
\text { distance }\end{array}$ & $\begin{array}{l}\text { First } \\
\text { race }\end{array}$ & Presenting symptoms & Comorbidities \\
\hline 30 & Female & Super sprint & Yes & Breathlessness & $\begin{array}{l}\text { Mild respiratory symptoms (cough) } \\
\text { I week prior to race }\end{array}$ \\
\hline 55 & Female & Sprint & No & Breathlessness & $\begin{array}{l}\text { Taking anti-depressants } \\
\text { Subsequence recurrence of symptoms }\end{array}$ \\
\hline 47 & Male & Sprint & Yes & Hemoptysis & Previous myocardial infarction, hypertension, raised cholesterol \\
\hline $2 \mathrm{I}$ & Female & Olympic & No & Breathlessness + hemoptysis & None \\
\hline 57 & Male & Olympic & No & Breathlessness & $\begin{array}{l}\text { Recent long haul flight } \\
\text { Similar previous episodes not investigated }\end{array}$ \\
\hline
\end{tabular}

Note: Data from Smith et al. ${ }^{16}$

Abbreviation: SIPE, swimming-induced pulmonary edema. 
of 36 subjects (mean age 48 years) with a history of SIPE, Peacher et al found that $72 \%$ had at least one significant concurrent medical condition (e.g., hypertension; cardiac dysrythmia, dysfunction, or structural abnormality; asthma, diabetes mellitus, or overweight). In contrast, the same authors found no obvious preexisting co-morbidities or cardiac risk factors in a literature review of 136 published cases of SIPE in military swimmers/divers. The patients in this review were much younger (mean age of 23 years) than the 36 cases. $^{5}$

More recently, Moon et $\mathrm{al}^{7}$ investigated 23 triathlon deaths that occurred during the swim leg. They compared the postmortem findings to a control group of living triathletes who were assessed by echocardiography. The authors reported that a greater proportion of the 23 triathletes who had died compared to the control group had left ventricular hypertrophy (LVH; which can cause a stiffer heart and might predispose to SIPE). On the basis of this result, the authors propose that SIPE may have been a significant cause of death in this group. ${ }^{7}$ This is an interesting finding but there are several possible pitfalls in its interpretation. Increased wall thickness and cardiac mass are common findings in trained athletes and are not necessarily pathological. Additionally, measurements of left ventricular (LV) wall thickness and heart mass do not reliably correlate with echocardiographic measures taken in life. Measurements of wall thickness postmortem are challenging as it is not possible to determine the phase of the cardiac cycle with any accuracy. The phase of contraction also determines the amount of mass attributable to blood at postmortem; echocardiographic measures are intended to estimate bloodless mass only.

Cases of SIPE are usually linked to exertion..$^{3,18,19}$ Exercise-induced pulmonary edema has been reported in land athletes, ${ }^{20}$ and is a well-known phenomenon seen in thoroughbred racehorses. ${ }^{21}$ Although exertion itself is a common factor, the onset of symptoms in SIPE does not seem to correlate with the duration of exertion, as many cases have been reported to occur soon after entering the water and it seems that immersion itself is the common etiological factor. ${ }^{22-24}$

Other proposed risk factors include cold water, ${ }^{1}$ overhydration, ${ }^{18}$ wetsuit use,,${ }^{14,23}$ and female gender. ${ }^{14}$ Cold water immersion causes an increase in central venous blood pooling and a subsequent increase in cardiac preload secondary to peripheral vasoconstriction; however, it should be noted that there have been reported cases in warm or tropical environments. ${ }^{25,26}$ Over-hydration exacerbates central venous pooling due to an increase in circulating plasma volume. ${ }^{18}$ Tight-fitting wetsuits may also cause external compression of peripheral vessels and limb deep veins, leading to central venous pooling and a subsequent increase in cardiac preload. ${ }^{27}$ Nevertheless, there are several cases of SIPE where a wetsuit was not worn., ${ }^{3,418}$ Cases are commonly but not exclusively seen in open water swimming/immersion; however, to the best of our knowledge, there has been at least one reported case. Gnadinger et al described a case of SIPE in a scuba diver in a swimming pool. ${ }^{28}$ Current views on the pathophysiology of SIPE are discussed in more detail in the following section.

\section{Pathophysiology}

The exact pathophysiology of SIPE still remains elusive; this is partly attributed to its sporadic nature and the difficulty in replicating it under experimental conditions. It is likely to be a combination of simultaneously occurring factors that together create a "perfect storm".

Predominant theories suggest the fundamental importance of redistribution of blood from the extremities, which occurs with immersion, ${ }^{29}$ leading to central blood pooling. ${ }^{30}$ This is enhanced further by peripheral vasoconstriction from cold water or a tight wetsuit. As a result, there is engorgement of the central veins leading to an increase in cardiac preload, reflected in an increase in left atrial pressure (usually estimated using the PAWP). ${ }^{8,31}$ This, in combination with an increased cardiac output from strenuous exercise, gives rise to elevated pulmonary artery pressures. Subsequently, the increased hydrostatic pressure results in alveolar edema and breakdown of the capillary-alveolar barrier. ${ }^{32,33}$ The prone horizontal swimming position may further exacerbate central pooling. Interestingly, there are a few cases of unilateral SIPE (in the submerged/dependent lung) in individuals swimming in the lateral decubitus position, suggesting either a mechanical effect or an effect of differential (external) pressure. ${ }^{19,34}$ Individuals with pathological LVH, and hence a stiffer heart, are less able to cope with increases in preload. Additionally, those with conditions that increase afterload, e.g., hypertension, aortic valve stenosis, or hypertrophic obstructive cardiomyopathy, would be expected to have a higher left atrial pressure at a given level of preload and would also be at greater risk of SIPE.

Casey et al propose a modification to this theory, arguing that athletes may augment their right ventricular (RV) stroke volume (SV) to a greater degree than their LV SV. They suggest that both ventricles can increase cardiac work to a very high degree, but that peripheral vasoconstriction (and perhaps external compression) increases LV afterload during exercise. Pulmonary vasodilatation means that $\mathrm{RV}$ afterload is increased to a substantially lesser degree and therefore there is a stroke volume difference $(\mathrm{RV}>\mathrm{LV})$, leading to congestion in the lungs. Such a mismatch would usually be compensated by increased LV work on the Frank-Starling curve, but if cardiac output is already maximal this may not be possible..$^{35}$ 
A recent study has advanced our understanding by measuring mean pulmonary artery pressure (MPAP) and PAWP in cases and controls exercising submerged in cold water. They found a statistically significant exaggerated rise in MPAP (34.0 $\mathrm{mmHg}$ vs $22.5 \mathrm{mmHg}[P=0.004])$ and PAWP $(11.0 \mathrm{mmHg}$ vs $18.8 \mathrm{mmHg}[P=0.028])$ in the 10 athletes with a previous history of SIPE compared to the control group, ${ }^{8}$ which they interpreted as confirming the central importance of hemodynamics (as opposed to capillary failure) in the development of SIPE. ${ }^{9}$ They suggest the mechanism for these elevated pressures is multifactorial, including higher blood volume, elevated venous tone, and reduced diastolic LV compliance. ${ }^{8}$

\section{Clinical presentation and management}

SIPE is characterized by the clinical features of pulmonary edema induced by immersion water and is related to vigorous physical activity. ${ }^{2}$ Grünig et al's recent review of 38 cases confirmed the most common presenting symptoms were dyspnea (79\%), cough (71\%), and hemoptysis $(68 \%){ }^{2}$ Water aspiration is a common differential diagnosis in this setting and may present with comparable features. Prompt clinical examination is invaluable as abnormal signs are frequently detected on auscultation, specifically basal crepitations and/ or rhonchi. Hypoxia is a common finding. ${ }^{2}$ A prompt accurate measurement of oxygen saturations in the pre-hospital setting, while nonspecific, adds objective information which may aid in monitoring and response to treatment. Clinicians should conduct an appropriate primary assessment and maintain a broad differential diagnosis when assessing the acutely unwell athlete.

In the pre-hospital setting, it is vital that appropriate resources are available for a safe water evacuation to prevent drowning, and minimum standard supplementary oxygen should be available, as oxygen was required in $77 \%$ of cases. ${ }^{2}$ Appropriate medical equipment and facilities should also be available at training locations as SIPE is not confined to competitions. Patients are likely to require transfer to hospital for further investigations and management. Clear communication regarding the potential diagnosis of SIPE should be made when transferring patients to alert colleagues of this relatively rare condition..$^{22}$

Pulmonary edema in the emergency department setting is most often confirmed by the use of chest X-ray (CXR). CXR was abnormal in $71 \%$ of cases reviewed. ${ }^{2}$ Point-of-care ultrasound (POCUS) is now frequently used in the prehospital setting, and could potentially be used to assess for SIPE at the waterside during events. It can confirm the presence of abnormal interstitial fluid in the lung to distinguish pulmonary edema from other causes of breathlessness. With a greater level of operator training, POCUS may be used to evaluate the heart and exclude major cardiac causes of pulmonary edema such as stress cardiomyopathy or myocardial infarction. POCUS was recently used to confirm pulmonary edema in the emergency department in a case of a highly trained young female swimmer who developed acute SIPE during open water training. ${ }^{36}$

Immediate removal from water is vital and can initiate symptoms resolution due the reverse of the hemodynamics promoting lung edema. In most cases, supplementary oxygen therapy is required. In combination with oxygen therapy, beta- 2 agonists are used in some cases $(37 \%),{ }^{2}$ perhaps due to the presence of rhonchi. However, there is also rationale that beta-2 agonists may accelerate the resolution of pulmonary edema. ${ }^{37,38}$ Intravenous/oral diuretics are sometimes used.

It is recommended that those who suffer with an episode of SIPE should have prompt evaluation of their cardiac and pulmonary physiology. ${ }^{5}$ Electrocardiography, echocardiography, stress echocardiography, measurement of cardiac enzymes, and coronary angiography may be indicated to rule out coronary disease or structural heart disease causing pulmonary edema. If clinically indicated, further investigations such as MRI renal angiogram and a 24-hour urinary collection for catecholamines may be required to rule out rare causes of flash pulmonary edema.

In most cases of SIPE, there is a rapid resolution of signs and symptoms within 48 hours ( $82 \%$ of cases). This often starts from simply exiting the water and providing supportive treatment. ${ }^{2}$ Regular monitoring and follow-up examination will ensure that patients are following this trajectory. It is important to recognize that there is a spectrum of severity of symptoms. This poses several challenges:

1. Triathletes/swimmers with mild symptoms may not seek help from medical teams as their symptoms improve on exiting the water and as they enter the bike phase adopting a more supine position. They may attribute their relative poor performance to various training factors.

2. They may be reluctant to attend hospital if symptoms are mild or have quickly resolved.

3. Lack of awareness among the admitting team may result in the patient being discharged without a formal diagnosis if symptoms have resolved by the time of assessment.

SIPE should be suspected in athletes who are unusually short of breath during or after swimming. Grünig et al identified that there were variations in the diagnostic pathways in reviewed cases. They proposed a checkpoint list to improve 
diagnostic accuracy. ${ }^{2}$ Athlete governing bodies, race organizers, and clinicians have a duty to promote awareness and ensure appropriate standards of care are being delivered. Athlete education programs will play a role in publicizing the recognition of SIPE.

\section{Recurrence rates and return to sport}

Recurrent episodes are common, and rates have been reported to be between $13 \%$ and $22 \%$ among scuba divers and swimmers. ${ }^{2-5,18}$ Authors from this manuscript found in their report that $40 \%(2 / 5)$ of triathletes had prior or subsequent episodes (Table 1). ${ }^{16}$ Recurrence of SIPE appears to be unpredictable and is not limited by age, sport, or environmental conditions. Adir et al found 16 of the 70 military swimmers had a recurrence of SIPE. All cases took place at least 3 months after the first incident. ${ }^{4}$ Furthermore, a fatal case of SIPE was described in a 51-year-old female recreational diver who logged 54 dives over the course of a year between episodes of SIPE. ${ }^{31}$ Carter and Koehle highlight that two of the three female triathletes in their group suffered with recurrence of SIPE. Among them, a 58-year-old female suffered at least four episodes over a 4-year period. On each occasion, symptoms started within 15 minutes of commencing swimming. However, not all of these episodes required hospitalization and in between the episodes she successfully completed two open water triathlons and multiple lake training sessions, further confirming the variable nature of this condition. ${ }^{23}$

It is of paramount importance that athletes are warned about recurrent episodes and should be emphasized that it is essential that a thorough evaluation of their cardiac and pulmonary physiology has been performed to look for any underlying causes of SIPE. ${ }^{5}$ Authors from this manuscript described a case of a 55-year-old female recreational triathlete who suffered with recurrent episodes of SIPE. The risk of potential recurrence was not highlighted to her during her hospital admission and she subsequently suffered a life-threatening episode when she returned to open water swimming. ${ }^{22}$

Athletes with a history of SIPE should be presumed to have a predisposition to recurrence. Although it is acknowledged that episodes of recurrence are unpredictable, these athletes should take care to swim in controlled environments to reduce the risk of drowning if a repeat episode was to occur. Spiteri et al suggest that starting swimming at a slower pace may be appropriate to reduce the recurrence rate. ${ }^{39} \mathrm{~A}$ gradually progressive step-wise return to swimming is a sensible approach. Prophylaxis has been suggested. New developments have shown that a single oral dose of sildenafil $50 \mathrm{mg}$ can lower PAP and PAWP. ${ }^{8}$ In clinical practice, Martina et al illustrated a case of a 46-yearold female ultra-triathlete with a history of at least five SIPE episodes who had no further recurrences during 20 subsequent triathlons while taking $50 \mathrm{mg}$ of sildenafil before each swim. ${ }^{9}$ These findings require sufficiently powered controlled studies to support this prophylactic use. Sildenafil is currently not on the prohibited list of the World Anti-Doping Code. ${ }^{40}$

\section{Conclusion}

Cases of SIPE will continue to occur as the popularity of open water swimming and similar water-based activities increase. Recent developments in the understanding of pulmonary vascular pressures have started to unravel the pathophysiology of this elusive condition. Further research to establish the incidence of SIPE for specific activities using appropriate common diagnostic criteria will help to define the extent of this condition. This in turn will help to distinguish predisposing factors.

Increased awareness among athletes, event medics, and emergency departments can assist in a prompt diagnosis and ensure optimum management, which includes advice regarding the return to activities and risk of recurrence. Further research is required to establish the role of prophylactic sildenafil in recurrent cases.

\section{Author contributions}

RS collected all studies and drafted the manuscript. JOMO, NS, and CK helped in drafting the manuscript. All authors approved the final version. All authors contributed toward data analysis, drafting and critically revising the paper and agree to be accountable for all aspects of the work.

\section{Disclosure}

The authors report no conflicts of interest in this work.

\section{References}

1. Wilmshurst PT, Nuri M, Crowther A, Webb-Peploe MM. Cold-induced pulmonary oedema in scuba divers and swimmers and subsequent development of hypertension. Lancet. 1989;1(8629):62-65.

2. Grünig H, Nikolaidis PT, Moon RE, Knechtle B. Diagnosis of swimming induced pulmonary edema - a review. Front Physiol. 2017;8:652.

3. Shupak A, Weiler-Ravell D, Adir Y, Daskalovic YI, Ramon Y, Kerem D. Pulmonary oedema induced by strenuous swimming: a field study. Respir Physiol. 2000;121(1):25-31.

4. Adir Y, Shupak A, Gil A, et al. Swimming-induced pulmonary edema: clinical presentation and serial lung function. Chest. 2004;126(2):394-399.

5. Peacher DF, Martina SD, Otteni CE, Wester TE, Potter JF, Moon RE. Immersion pulmonary edema and comorbidities: case series and updated review. Med Sci Sports Exerc. 2015;47(6):1128-1134.

6. Edmonds C. The evolution of scuba divers pulmonary edema. Undersea Hyperb Med. 2016;43(2):83-91. 
7. Moon RE, Martina SD, Peacher DF, Kraus WE. Deaths in triathletes: immersion pulmonary oedema as a possible cause. BMJ Open Sport Exerc Med. 2016;2(1):e000146.

8. Moon RE, Martina SD, Peacher DF, et al. Swimming-induced pulmonary edema: pathophysiology and risk reduction with sildenafil. Circulation. 2016;133(10):988-996.

9. Martina SD, Freiberger JJ, Peacher DF, et al. Sildenafil: possible prophylaxis against swimming-induced pulmonary edema. Med Sci Sports Exerc. 2017;49(9):1755-1757.

10. Cochard G, Henckes A, Deslandes S, et al. Swimming-induced immersion pulmonary edema while snorkeling can be rapidly life-threatening: case reports. Undersea Hyperb Med. 2013;40(5):411-416.

11. Wenger M, Russi EW. Aqua jogging-induced pulmonary oedema. Eur Respir J. 2007;30(6):1231-1232.

12. Pons M, Blickenstorfer D, Oechslin E, et al. Pulmonary oedema in healthy persons during scuba-diving and swimming. Eur Respir J. 1995;8(5):762-767.

13. Keuski BM. The incidence of swimming-induced pulmonary edema (SIPE) in trainees at U.S. Navy dive training facilities. 2011. Available from: http://www.dtic.mil/dtic/tr/fulltext/u2/a561894.pdf. Accessed April 10, 2108.

14. Miller CC, Calder-Becker K, Modave F. Swimming-induced pulmonary edema in triathletes. Am J Emerg Med. 2010;28(8):941-946.

15. Ma JL, Dutch MJ. Extreme sports: extreme physiology. Exercise-induced pulmonary oedema. Emerg Med Australas. 2013;25(4):368-371.

16. Smith R, Parkin J, Knight N, Kipps C. The incidence of swimminginduced pulmonary oedema during mass-participation triathlon races: optimising athlete safety. Br J Sports Med. 2017;51(4):391-391.

17. Slade JB, Hattori T, Ray CS, Bove AA, Cianci P. Pulmonary edema associated with scuba diving: case reports and review. Chest. 2001;120(5): 1686-1694.

18. Weiler-Ravell D, Shupak A, Goldenberg I, et al. Pulmonary oedema and haemoptysis induced by strenuous swimming. BMJ. 1995;311(7001) 361-362.

19. Mahon RT, Kerr S, Amundson D, Parrish JS. Immersion pulmonary edema in special forces combat swimmers. Chest. 2002;122(1):383-384

20. Bates ML, Farrell ET, Eldridge MW. The curious question of exerciseinduced pulmonary edema. Pulm Med. 2011;2011:361931.

21. West JB, Mathieu-Costello O, Jones JH, et al. Stress failure of pulmonary capillaries in racehorses with exercise-induced pulmonary hemorrhage. J Appl Physiol (1985). 1993;75(3):1097-1109.

22. Smith R, Brooke D, Kipps C, Skaria B, Subramaniam V. A case of recurrent swimming-induced pulmonary edema in a triathlete: the need for awareness. Scand J Med Sci Sports. 2017;27(10):1130-1135.

23. Carter EA, Koehle MS. Immersion pulmonary edema in female triathletes. Pulm Med. 2011;2011:261404.
24. Deady B, Glezo J, Blackie S. A swimmer's wheeze. CJEM. 2006;8(4): 281, 297-288.

25. Kwek W, Seah M, Chow W. Swimming-induced pulmonary edema in a tropical climate: a case report. Undersea Hyperb Med. 2017;44(3):293-296.

26. Yamanashi H, Koyamatsu J, Nobuyoshi M, Murase K, Maeda T. Exercise-induced pulmonary edema in a triathlon. Case Rep Med. 2015;2015:968152.

27. Lundgren CEG, Miller JN. The Lung at Depth. New York: Dekker; 1999.

28. Gnadinger CA, Colwell CB, Knaut AL. Scuba diving-induced pulmonary edema in a swimming pool. J Emerg Med. 2001;21(4):419-421.

29. Arborelius M, Ballidin UI, Lilja B, Lundgren CE. Hemodynamic changes in man during immersion with the head above water. Aerosp Med. 1972;43(6):592-598.

30. Wester TE, Cherry AD, Pollock NW, et al. Effects of head and body cooling on hemodynamics during immersed prone exercise at 1 ATA. J Appl Physiol (1985). 2009;106(2):691-700.

31. Edmonds C, Lippmann J, Lockley S, Wolfers D. Scuba divers' pulmonary oedema: recurrences and fatalities. Diving Hyperb Med. 2012;42(1): 40-44.

32. Tsukimoto K, Mathieu-Costello O, Prediletto R, Elliott AR, West JB. Ultrastructural appearances of pulmonary capillaries at high transmural pressures. J Appl Physiol (1985). 1991;71(2):573-582.

33. West JB, Tsukimoto K, Mathieu-Costello O, Prediletto R. Stress failure in pulmonary capillaries. J Appl Physiol (1985). 1991;70(4):1731-1742.

34. Lund KL, Mahon RT, Tanen DA, Bakhda S. Swimming-induced pulmonary edema. Ann Emerg Med. 2003;41(2):251-256.

35. Casey H, Dastidar AG, MacIver D. Swimming-induced pulmonary oedema in two triathletes: a novel pathophysiological explanation. $J R$ Soc Med. 2014;107(11):450-452.

36. Alonso JV, Chowdhury M, Borakati R, Gankande U. Swimming-induced pulmonary oedema an uncommon condition diagnosed with POCUS ultrasound. Am J Emerg Med. 2017;35(12):1986.e1983-1986.e1984.

37. Licker M, Tschopp JM, Robert J, Frey JG, Diaper J, Ellenberger C. Aerosolized salbutamol accelerates the resolution of pulmonary edema after lung resection. Chest. 2008;133(4):845-852.

38. Groshaus HE, Manocha S, Walley KR, Russell JA. Mechanisms of beta-receptor stimulation-induced improvement of acute lung injury and pulmonary edema. Crit Care. 2004;8(4):234-242.

39. Spiteri D DR, Micallef-Stafrace K, Xuereb RG. Recurrent swimminginduced pulmonary oedema (SIPE) in a triathlete: case report. Int Sports Med J. 2011;12(3):141-144.

40. Agency WA-D. The World Anti-Doping Code: International Standard 2017. 2017. Available from: http://www.wada-ama.org. Accessed December 2017
Open Access Journal of Sports Medicine

\section{Publish your work in this journal}

The Open Access Journal of Sports Medicine is an international, peer-reviewed, open access journal publishing original research, reports, reviews and commentaries on all areas of sports medicine. The journal is included on PubMed. The manuscript management system is completely online and includes a very quick and fair
Dovepress

peer-review system. Visit http://www.dovepress.com/testimonials.php to read real quotes from published authors. 